\title{
Pilot study of records of shared care for people with mental illnesses
}

\author{
B Essex, R Doig, J Renshaw
}

\begin{abstract}
Objective-To develop and evaluate a record of shared care to be held by the patient designed to increase the effectiveness of long term care of patients with severe mental illness.

Design-Questionnaires completed by medical staff, community psychiatric nurse, and patients to evaluate the shared care record.

Setting-General practices, a psychiatric outpatient clinic, and a mental health resource centre in south east London.

Patients -84 Patients held shared care records over an 18 month period. They were selected by general practitioners, a psychiatrist, or a community psychiatric nurse, the criterion being that their care was shared between the general practitioner and the psychiatrist or community psychiatric nurse. Patients who had been admitted to hospital several times with short remissions were excluded.

Main outcome measures-Patients were asked to complete a questionnaire to assess their views on the acceptability, usefulness, and problems of the shared care record. A questionnaire for health staff was designed to identify patients for whom the shared care record was most and least appropriate. It also assessed the patients' compliance and the way the record affected communication between all concerned.
\end{abstract}

Results-Patients found the shared care records very acceptable and were enthusiastic about their use. They valued being consulted about what was recorded and found the record of their treatment and progress useful. Patients also thought that they were in a better position to challenge their doctor. Those least likely to comply were people with severe paranoia. The acceptability of the record to patients greatly exceeded that to the psychiatrists and nurse managers, none of whom were interested in using the record. Communication among health staff was greatly improved by the shared care record, and it facilitated the identification of potentially dangerous drug interactions.

Conclusions-Shared care records were acceptable to patients with severe mental illnesses, increased the patients' autonomy, and improved communication and the effectiveness of shared care. Obstacles to further development of this approach relate to the attitudes, perceptions, and anxieties of the doctors, nurses, and managers and can be overcome.

Kirkdale Resource Centre, London SE26

J Renshaw, RMN, community psychiatric nurse

Correspondence to: Dr Essex.

BrMed f 1990;300:1442-6
In the United Kingdom $1 \cdot 2 \%$ of the population have a severe mental illness that causes distress and disruption to them and their families. A practice with 11500 patients can expect to have 115 patients with schizophrenia or other forms of psychosis on its list. These patients' needs cannot be met by one group of professionals, and care is often shared. Carers include relatives, general practitioners, community psychiatric nurses, psychiatrists, psychologists, social workers, practice nurses, and staff at resource or mental health centres. Casualty departments, deputising services, and voluntary organisations may also provide care. A recent white paper emphasised the importance of effective coordination between health and social service authorities, primary care teams, and voluntary agencies. ${ }^{1}$ Care in the community, however, is often episodic, fragmentary, and confusing. The roles and responsibilities of patients, carers, and professionals are often unclear. Drugs can be started, stopped, and changed and their doses adjusted by the patient, psychiatrist, or general practitioner without one letting the others know. If a patient is discharged from follow up in the clinic or practice other carers are not always informed, and when patients default from follow up it may be wrongly assumed that the hospital or the general practitioner is still providing care. There is no central source of information about current management and progress.

The care of diabetic patients and pregnant women provides a model for shared care. Patients, doctors, specialist nurses, community workers, and voluntary organisations all have relevant skills, and the roles and responsibilities of each are clearly defined. The patient holds the record of shared care, which has been specifically designed to provide up to date information for the patient as well as for the carers.

The idea of applying this concept to patients with mental illnesses is not new, ${ }^{2}$ but as far as we know it has not been tried and evaluated in the United Kingdom. Doctors are criticised by patients, who say that they do not listen enough and do not consult them when making decisions about their care. ${ }^{5}$ Yet it is doubtful whether shared care can succeed without more radical and active participation of the patients. ${ }^{4}$

\section{OBJECTIVES}

This research project was started in 1987 to develop and evaluate a record of shared care held by patients. The record was designed to increase the effectiveness of long term care for patients with severe mental illness, and patients were asked to take it to each consultation with the general practitioner, community psychiatric nurse, psychiatrist, or psychologist. It was not intended to replace the hospital or general practice records. The main objectives were to improve communication between patients and all their professional carers, reduce the need for correspondence between carers, provide accurate and up to date information when clinic notes were mislaid, and prevent potentially dangerous prescribing. In addition, we hoped that the record would help patients to recognise problems and take appropriate action and increase their autonomy.

We used the shared care record to study whether 
patients with severe mental illness could use a shared care record; whether such a record could increase the patients' participation in their long term care; whether patients could be relied on to keep and provide information about current management and progress; and whether professionals were willing to allow patients autonomy - a prerequisite to effective shared care. Thus the hypothesis to be tested was that many patients with mental illnesses could provide an appropriate and cost effective source of information for all concerned with their long term management.

\section{Patients and methods}

The box shows the information recorded in the shared care record. Inside the back cover there was space to keep the appointment and repeat prescription cards. Many people were asked to comment on the drafts of the record, and the final version incorporated the criticisms of both patients and health staff.

\section{INTRODUCING THE CONCEPT OF SHARED CARE RECORDS}

An initial meeting was held for people who cared for patients with serious mental illnesses in the local community, including general practitioners, community psychiatric nurses, the district psychiatrist, social workers, occupational therapists, careworkers and their coordinator, and representatives of local voluntary organisations. The problems of shared care were discussed and the concept of the shared care record was introduced.

We also tried to interest the general practitioners in 10 general practices, 25 local psychiatrists, and eight heads of university departments of general practice. The project coordinator, who was also a community psychiatric nurse working in the local resource centre, also visited several nurse managers to try to get them to participate. She remained in contact with all participating professionals throughout the study, identifying and dealing with any problems encountered.

\section{SELECTION OF PATIENTS}

Patients were introduced to the idea of the shared care record by their general practitioner, the resource centre's community psychiatric nurse, or the consultant psychiatrist. Patients who had been discharged from long stay hospitals and were living in hostels supervised by a careworker were told about the record by their careworker.

All patients had to have a mental illness that needed long term care from a general practitioner and one or more of a psychiatrist, psychologist, or community psychiatric nurse. Patients were excluded if they had been admitted to hospital several times with short remissions. Patients with severe delusional states were included provided that they fulfilled the above criteria.

The general practitioners participating in the study selected patients whom they knew fulfilled the above criteria. In addition, the psychiatrist selected suitable patients from those about to be discharged from the acute admission unit as well as those attending outpatient clinics.

\section{PARTICIPATION OF PATIENTS}

Guidelines were provided to help doctors, nurses, and other carers to educate patients about the shared care record. Patients were allowed to discuss their worries about using the record, and it was made clear that they did not have to make a quick decision whether or not to use it.

\section{RECORDING OBSERVATIONS}

Doctors and nurses were taught to record information using non-technical words and to record observations in the patient's own words whenever possible

\section{Information contained in patients' shared} care record

- The patient's name, address, and telephone number, next of kin, general practitioner, psychiatrist, community psychiatric nurse, and social worker

- The psychiatric and other relevant diagnoses

- The drugs being taken when the record was set up and subsequent changes to the prescription

- Specific services available to the patient-for example, rehabilitation, day centre, or occupational therapy

- The responsibilities of different carers

- Information for the patient about why the treatment is being continued, who is caring for him or her, when to worry about the illness, what to do, and who else might help

- Observations made at follow up

- The patient's own observations

- for example, phrases such as "anxious about," "fears that," "feels that," "people say that I," and "no longer troubled by" were written down. Patients were then asked if the observations represented an accurate statement.

Whoever initiated the shared care record informed other carers that this had been done. A standard letter was drafted that stated not only that the patient had been given a shared care record but also what its goals were; that it was to be used by all carers but did not replace the practice or clinic notes; that the patient's record needed to be tagged to indicate the existence of a shared care record; that any other carers should be informed about the record; and how to record observations in a way that was both accurate and acceptable to the patient.

The health staff saw many patients during the study, only a few of whom had a shared care record. The practice or hospital records were tagged in some way by the records initiator so that the doctor or nurse was reminded that a shared care record existed.

The shared care records were evaluated by questionnaire surveys of the patients and the carers, coordinated by the resource centre's community nurse. Patients were asked whether they found the shared care record useful; whether the information it contained was useful to them, and if so what was most useful; what additional information they would have liked; and whether they liked to see what was written about them. Patients were also asked to comment about aspects of the record that they liked or disliked and those that they thought could be improved.

To preserve confidentiality the questionnaire had to be administered by the patient's doctor or psychiatric nurse rather than an unbiased observer. Although this may have introduced a bias towards positive comments, criticisms were also expressed. Patients were reassured by the fact that the questionnaires were anonymous.

The second questionnaire was designed to evaluate the views and experiences of the professionals who used the shared care records. They were asked how many shared care records they had initiated; how many they used that had been initiated by others; what mental illnesses the patients had; who shared the care of the patients; how many patients with shared care records had moved or defaulted from all follow up appointments; and the percentage of times that each patient had brought his or her shared care record to follow up visits $(<50 \%, 50-75 \%,>75 \%)$. They were also asked about the groups of patients for whom they considered the questionnaire was most and least acceptable and appropriate and the ways in which the record affected communication with other carers, 
management and follow up of patients, and the doctorpatient relationship. They were invited to suggest how the format could be improved and further what information they would like to see recorded. These questionnaires were completed by the psychiatrist, the community psychiatric nurse, and 12 general practitioners.

\section{Results}

EVALUATION

During the 18 month study a total of 84 patients were given shared care records. Most of the patients had schizophrenia or other forms of chronic psychotic illness. Their care was shared between the general practitioner, the community psychiatric nurse, and the psychiatrist. The psychiatrist initiated the record with 24 patients, the nurse with 15 , the general practitioners with 30 , and the hostel careworker with 15 . Patients used the shared care records for three to 18 months.

Fifty one patients completed the questionnaire. Fourteen had moved out of the district before the final evaluation and four were lost to follow up. The hostel careworker left her job before the scheme was evaluated, and although 15 of her clients had been using the records, they were not asked to complete the questionnaires.

\section{ACCEPTABILITY TO PATIENTS}

Most patients found the idea of a shared care record acceptable once it had been explained that the record could improve communication with their carers, they could decide who used it and whether the observations recorded were accurate and acceptable, they kept the record and brought it to each visit with a carer, and it provided useful information about what to do if they had any problems. The box shows some of the patients' comments about the shared care record taken from the questionnaire. Almost all (51) patients said that they liked to see what had been written about them and appreciated being asked if the comments were accurate and acceptable before they were recorded. Many complained about the legibility of the handwriting. They liked holding their own records and some thought that all records should be available to patients. The comments about treatment were representative of the feelings of most patients, who said that this was one of the most useful features of the shared care record.

Many patients disliked the initial title of the record - the mental health shared care record-and at their request this was changed to the shared care record. Patients differed in their attitude to having the diagnosis recorded: some did not want this information on the record and others did not mind. Patients were asked if they would prefer to have their diagnosis omitted from the record or would like to suggest a more acceptable diagnosis.

Some patients were anxious about having their names and telephone numbers on the record in case it got lost and thought that a number or code might be preferable. Most found the information contained in the record useful and appreciated having advice about what to do when things went wrong. Patients noted that one deficiency was that no reference was made to claims and benefits they were receiving, such as the attendance allowance, and this will be included in the revised version of the record.

\section{ACCEPTABILITY TO HEALTH STAFF}

Attempts were made to interest as many psychiatrists, general practitioners, and community psychiatric nurses as possible in the pilot study. Discussions were held with more than 25 psychiatrists but none participated in this project. Most psychiatrists regarded the scheme with great misgivings. They were
Patients' comments about the shared care record

\section{General}

The comments at least showed the doctors are not asleep and are listening

Reading the comments and knowing what is said allows you to challenge the doctor

Yes, doctors should tell me what they write about me.

It documents my mood swings

A way of knowing if you have put over correctly how you are feeling

Good to see if the doctor understood how you feel

It is a record of present and past progress

Doctors take what I say seriously and write it down

Seeing what doctors write about me and being able to disagree makes me feel more in control

Trying to win me over by false democracy

Treatment

Handy to check what tablets I am taking for other doctors

Made me feel very aware that I was taking drugs, and I prefer to forget about this

Useful when stopped by police to prove that my drugs were prescribed by a doctor

Useful but my general practitioner would not sign it, so I wrote the change of treatment myself

If I am taken ill there is something to tell people what tablets I am taking

Useful when the hospital changes the treatment and does not write to the general practitioner

I can see the pattern of treatment, and how I was over time

Easier to check out whether my symptoms were due to side effects of treatment

Not having to answer questions about treatment changes that I am not sure about

As an epileptic taking anticonvulsants and steroids permanently, I keep the book in my handbag and know that if there was a problem people would know which drug I was taking

unhappy about allowing patients to have access to their own records. Some of the reasons given were that they were more interested in minor psychological disorders in primary care than in people with psychotic illnesses; that general practitioners were trying to participate in care that was not their concern; that general practitioners in their district either were unable to look after patients with severe psychotic illnesses or lacked the motivation to do so; that they were reluctant to meet with general practitioners to discuss the possibility of shared care; that depot clinics were better than shared care schemes; and that the psychiatrist together with the community psychiatric nurse were best able to meet the needs of this group of patients and that shared care was not necessary.

Those psychiatrists already working closely with general practitioners were thought to be most likely to participate in this study. Despite expressing initial interest and requesting samples of the shared care records and educational material, however, they did not participate. The reasons for this are not known.

The response of the psychiatrists cannot be regarded as representative of the general attitude of psychiatrists towards shared care. They merely reflect the responses of a few consultants within the South East Thames region, many of whom were attached to teaching hospitals.

The eight professors of general practice who were 
approached thought that shared care records were a low priority at that time. The lack of interest shown by any of the community psychiatric nursing managers with whom the project was discussed was very disappointing. There seemed to be a belief that no more new procedures could be tackled, possibly because of the many administrative and management changes the service had had to cope with, together with the reduction in health staff and resources at a time when there was great uncertainty about the reorganisation of community services.

More encouraging was the response from the general practitioners, $12(30 \%)$ of whom used the shared care records with suitable patients. The most positive finding was that the patients' enthusiasm far exceeded that of the psychiatrists, general practitioners, nurses, or managers.

\section{COMPLIANCE}

Of the 84 patients, $55 \%$ took their records to more than $75 \%$ of follow up visits, $17 \%$ took them to between $50 \%$ and $75 \%$, and $12 \%$ took them to less than $50 \%$. Surprisingly good compliance was found among patients discharged from long stay hospitals into special housing in the community.

Compliance was poorest among patients whose illness produced intense feelings of paranoia or who had delusions that the media or state organisations were conspiring against them. Such patients had great anxieties about their records getting into the wrong hands. Poor compliance was also noted in patients who had difficulty accepting that they had a mental illness and in those who did not want to take responsibility for any aspect of their illness.

When patients moved out of the district they were encouraged to take the shared care record to their new doctor as it provided an up to date summary of current treatment and progress. This is especially important as it may take some months for records to reach the new doctor.

The shared care record seemed most acceptable to patients who: had insight into and interest in their own problems; accepted that they had a mental illness that needed long term treatment; had frequent contact with a hospital or the community services, or both; thought that holding their own records gave them greater autonomy; liked to participate in their treatment and were motivated to attend follow up appointments; and had physical as well as mental illnesses.

A survey of patients with chronic mental illness found that $53 \%$ had one or more physical illnesses and that this had considerable implications for possible drug interactions. ${ }^{5}$ The shared care record was shown to be useful for identifying possibly dangerous interactions. It was thought to be most appropriate for patients who were receiving injections elsewhere or whose treatment was complex and often changed, who were receiving care from various agencies and staff involved, or who had frequent contacts with a psychiatrist or nurse.

\section{COMMUNICATION}

Professionals using the shared care record believed that it improved their communication with thei patients. It helped them to know who else was caring for the patient and how often and enabled them to adjust their input accordingly. This increased the efficiency of follow up and prevented duplication of effort. The records also identified what services had been initiated, whether they were taken up by the patient, and when they were terminated; enabled rapid and efficient transfer of information about drugs and response to treatment; and allowed potentially dangerous interactions between drugs to be recognised more rapidly - for example, lithium and non-steroidal anti-inflammatory drugs. The shared care record encouraged the users to record relevant data.

Communication through the shared care record depended totally on the agreement of all health staff to use the resord and to remember to ask the patient for it. To do this most people needed to think of the record as a valuable management tool. Many observed that it made patients participate more in their long term care. Patients commented that having greater access to information about themselves improved their relationship and communication with health staff.

The shared care record made everyone more careful about what to record and how to word it in a way that ensured both accuracy and acceptability to the patient. Other advantages included helping to ensure safe management when notes got mislaid and reinforcing and standardising education about what to do if problems arose or relapse occurred. The record also informed the community psychiatric nurses in the resource centre about drugs prescribed - the first time they had received such information. The nurses could more readily identify side effects of drugs, and patients could be referred back to their doctor when necessary. One patient was identified who had been prescribed a monoamine oxidase inhibitor by her general practitioner when her record indicated that she had recently started treatment with a phenothiazine.

One important observation was that the patient's interest had to be sustained by the health workers. If they did not ask for or use the record the patient would not bring it next time. This is a danger when staff changes occur, and it is essential to educate new staff about the aims and uses of the shared care record as soon as possible.

\section{Discussion}

One goal of this project was to identify the difficulties encountered when attempts are made to introduce innovations in the care of patients with serious mental illness. Our pilot study showed that many patients with schizophrenia were willing to use a shared care record and found it useful and acceptable. The main obstacles to further development of this approach relate to the attitudes, perceptions, anxieties, and fears of the doctors, nurses, and managers.

Many psychiatrists doubted the ability of general practitioners to look after schizophrenic patients, and many general practitioners were reluctant to accept responsibility for their long term care. Although many patients with schizophrenia are never referred to a psychiatrist, there is great reluctance to consider the concept of shared care as feasible, useful, or desirable. The patient's role is seen by many doctors as that of passive recipient rather than active participant, and this militates against the concept and practice of shared care.

Some psychiatrists thought that shared care was a challenge to their authority. Much education is needed to help people to recognise that patients and carers need a combination of special skills from several different professionals. Many general practitioners are not allowed to make direct referrals to community psychiatric nurses, ${ }^{6}$ and this makes effective teamwork and use of specialist skills difficult to achieve. The need to refer a patient to a psychiatrist to contact a nurse is both costly and inefficient and represents a lost opportunity in terms of shared care. ${ }^{7}$ Our study, however, showed that the shared care record is practical, effective, and acceptable to certain patients. It can clarify the roles and responsibilities of different people; improve communication between patients and all professionals involved in long term care; provide accurate and up to date information when notes get mislaid; help patients and carers to recognise problems 
and take appropriate action to prevent a crisis; help to prevent potentially dangerous drug interactions; and increase the autonomy of patients.

Compliance and acceptability were high among a wide range of patients. Even patients who were very deluded were still able to use and value their shared care record, and many more patients could provide a central source of information about their treatment and progress. There is considerable evidence that patients want to participate actively in their own health care rather than be passive participants. More emphasis is now being placed on what patients want, and recently both MIND and the National Schizophrenia Fellowship have initiated user groups. ${ }^{8}$ Some of the groups also participate in planning mental health services and hospital practices, ${ }^{9}$ yet user participation is not directly mentioned in the recent white paper on community care ${ }^{1}$ or in the Royal College of Psychiatrists' paper on community care..$^{10}$ The King's Fund has called for increased collaboration between patients, planners, and managers in mental health care. "This could facilitate the introduction of innovations such as the shared care record. Collaboration between patients, planners, and managers could help to resolve some of the fears and anxieties of patients, nurses, and doctors providing long term care.

The quality of care depends ultimately on access to up to date information and good communication. The most relevant conclusions drawn from this study were that many patients with chronic psychotic illnesses can hold shared care records and appreciate their value. These records lead to improved communication, and the patients themselves became the best source of information about current management and progress. Patients' autonomy was increased, and this can repre- sent a threat to some professionals who care for people with mental illnesses in the community. Our research identified some of the obstacles that need to be tackled before shared care records become more widely used. With patience, education, and a commitment to teamwork most of them can be overcome, and when this happens shared care could become a reality.

This research was supported by a grant from the South East Thames Primary Care Development Fund. We thank the many patients who participated in the study and the general practitioners: Drs G Ah-Moye, B Fisher, S Hilton, P TudorMiles, B Northover, R Pietroni, A Platman, J Rosenthal, S Savage, J Sikorski, D Thompson, S Thomas, and P White. We also thank the staff of the South East Thames region who administered the research funds. Copies of the record may be obtained from Dr Essex.

1 Secretaries of State for Wales, Scotland, and Northern Ireland. Caring for people: community care in the next decade and beyond. London: HMSO, 1989. 2 Marks B, Swindells S. Blueprint for a psychiatric cooperation card. $f(R \mathrm{Coll}$ Gen Prct 1983;33:459-60.

3 Lavender A, Holloway F, eds. Community care in practice. Chichester: Wiley, 1988

.

5 Honig A, Pop P, Tan ES, Philepson H, Romme MAJ. Physical illness in chronic psychiatric patients from a community psychiatric unit. $B r f$
Psychiatry 1989;155:58-64.

6 Briscoe $M$, Wilkinson G. General practitioners' use of community psychiatric nursing services: a preliminary survey. $\mathcal{F} R$ Coll Gen Pract 1989;39:412-4.

7 Horder J. Working with general practitioners. Br I Psychiatry 1988;153. 513-20

8 Winn D. Human network halts the spiral of despair. Independent $1989 \mathrm{Feb}$ 28:13.

9 Good Practices in Mental Health and the Camden Consortium. Treated well? A code of practice for psychiatric hospitals. London: Good Practices in Mental Health, 1988

10 Royal College of Psychiatry. Caring for a community. London: Royal College of Psychiatry, 1988.

1 Smith H. Collaboration for change: partnership between service users, planners and managers of mental health services. London: King's Fund, 1988.

(Accepted 27 February 1990)

\section{THE MEMOIR CLUB}

An energetic young man claimed to be the headman of the village, and Karre entered into negotiations with him for the guarding of the car and tent while we went up the mountain and for the provision of a guide and porters. Being accustomed to the occasional party trekking up Mt Elgon, the headman was not disposed to allow us to travel on the cheap. His rates started at the exorbitant, slid down gradually to the unreasonable, and finally reached a level, after more than an hour's bargaining, of the reluctantly acceptable. Kåre went through the whole procedure skilfully: I speak as a connoisseur of a charade that, unlike most of my countrymen, I always enjoyed. For goods in shops or fruit at the wayside, for the hire of a car or the purchase of a rug, I always entered with spirit into the great game of getting somewhere near the real price by acting, first, agreeable attention to the vendor's welcome, then astonished horror at his price, impatience at his presumption, putting on a puzzled frown as his expectation became less outrageous, but, as his price suddenly stuck, once again expressing annoyance, flouncing out of the shop, though, in response to his pursuit of me to the road outside, yet again becoming interested, then, on having another look at the goods, proposing another reduction in price till, yes, that's about it, but another $10 \%$ off - and he agrees, all smiles and gratitude at having been able to sell me something for about $50 \%$ more than his countrymen would have paid for it. So we part at the door as friends will say goodbye after watching a play at the theatre, pleasurably reliving the performance in the memory, both vendor and purchaser relaxed by the emotional relief of being convinced that he got a good bargain.

Finally, we took to the track through cultivated fields that led up to the steeper slopes of the mountain. When the forest itself came into view an hour later and we had reached the end of the patches of corn and peas, our porters suddenly dropped their loads and without a word disappeared from sight over a low hill. Our guide quickly followed them. On pursuing them we found them already lying on the ground by a hut from which beer was dispensed. Rather as a petrol station will advertise "last petrol before the motorway," so here was the last beer before the real ascent began. Few delays can be more exasperating to a botanist eager to reach good collecting ground than to be left stranded by weedy patches of vegetables while his porters and guide drink away the morning hours with successive pints of pombé. So it was with annoyed but relieved expressions that we welcomed back the guide some time later and he led us away from this den of iniquity up into the forest. But what about the porters? we asked. They will follow, he said. We trudged away with some trepidation.

From Reap a Destiny: Divagations of a Taoist by Douglas Swinscow. Published under the BMF's Memoir Club imprint. ISBN 072790255 5. Price: Inland $£ 14.95$; abroad $£ 17.50$; USA $\$ 29.00$. BMA members: Inland $£ 13.95$; abroad $£ 16.50$; USA $\$ 27.00$.

When Barbara Castle was Secretary of State, she gave a very fair wind to the doctrinaire objective of extruding private practice from the NHS. In this way, a shallow interpretation of fairness prejudiced a useful source of revenue for the service; forced consultants to waste time and energy in acquiring facilities for private practice outside the service; and, worst of all, deprived patients in the private sector (which is not illegal) from access to the special facilities found in hospital, and even in many cases from adequate night cover in emergency. In the event, this has been one of the main factors in the expansion of the private sector in recent years, which has converted it from a marginal activity to an important provider of medical care; Mrs Castle's contribution to this could well be marked by a statue in the forecourt of the Cromwell or Wellington Hospital.

My other antiheroine is, of course, Margaret Thatcher, who was an excellent Secretary of State for Education and Science (the cut in school milk being marginal, even if symptomatic). A heady mixture of monetarism and power has not turned out well for the universities (whose medical faculties contribute considerably to health care) or for the NHS. Charging so called realistic fees to postgraduate students from overseas has cut off selectively what was once a remarkably cheap way of spreading British influence throughout the world. What a politician says during the run up to an election may not be evidence, but when she said, "The health service is safe with us," I felt a twinge of anxiety - no politician had felt it necessary to say this before.

From Recollections and Reflections by Douglas Black. Published under the BMF's Memoir Club imprint. ISBN 072790209 1. Price: Inland £14.95; abroad $£ 17.50$; USA $\$ 29.00$. BMA members: Inland $£ 13.95$; abroad $£ 16.50$; USA $\$ 27.00$ 